\title{
КОРРЕЛЯЦИОННЫЕ ОТНОШЕНИЯ ПОКАЗАТЕЛЕЙ ПРОСТРАНСТВЕННО-ВРЕМЕННО́Й ОРГАНИЗАЦИИ МОЗГА КАК РЕАЛИЗАЦИЯ СИСТЕМНОГО ПОДХОДА В ИЗУЧЕНИИ ПСИХОФИЗИОЛОГИЧЕСКИХ ПРОЦЕССОВ
}

\section{CORRELATION RELATIONSHIPS \\ OF SPATIAL-TIME BRAIN ORGANIZATION \\ AS A SYSTEM APPROACH IN THE STUDY OF PSYCHOPHYSIOLOGICAL PROCESSES \\ T. Yadrischenskaya}

Summary: The article examines the correlation relations of the indicators of the spatio-temporal organization of the brain from the side of the systems approach. During the study, reliable values of the correlation coefficient were established between the individual asymmetry profile as a spatial indicator and temporal characteristics of the system, such as the «individual» minute, the speed of a simple visual-motor reaction, circadian chronotype. The discovered relationships are a manifestation of one of the properties of the multidimensional space-time system of the brain.

Keywords: spatio-temporal organization of the brain, correlation relationships, systemic approach, individual asymmetry profile, speed of simple visual-motor reaction, circadian chronotypes, individual minute.

\author{
ядрищенская Татьяна Васильевна \\ К.б.н., дочент, Тихоокеанский государственный \\ университет, г. Хабаровск \\ tagir.on-line@mail.ru
}

Аннотация: В статье рассматриваются корреляционные отношения показателей пространственно-временной организации мозга с позиций системного подхода. В ходе исследования установлены достоверные значения коэффициента корреляции между индивидуальным профилем асимметрии как пространственным показателем и временными характеристиками системы, такими как «индивидуальная» минута, скорость простой зрительно-моторной реакции, суточный хронотип. Обнаруженные взаимоотношения являются проявлением одного из свойств многомерной пространственно-временной системы мозга.

Ключевые слова: пространственно-временна́я организация мозга, корреляционные отношения, системный поход, индивидуальные профиль асимметрии, скорость простой зрительно-моторной реакции, суточные хронотипы, индивидуальная минута.

\section{Введение}

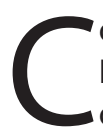

огласно теории функциональных систем П.К. Анохина, в основе поведения, как активного отношения организма со средой, лежат качественно специфические системные процессы или процессы организации элементов в систему. Функциональные системы - «это динамические, саморегулирующиеся организации, все составные компоненты которых взаимодействуют достижению полезных для системы и метаболизма организма в целом приспособительных результатов» [1]. Наличие функциональных систем позволяет регулировать поведение, причем наиболее важным аспектом данного подхода было постулирование иерархичности и динамического характера систем. Системный принцип изучения различных сторон функционирования и деятельности организма человека предполагает наличие многомерных и многоуровневых связей как в пределах отдельной частной конституции, так и между ними [3]. Целостность индивидуальности лежит в основе того факта, что любое воздействие хотя бы на один из уровней (биохимический, физиологический, психологический и др.) неизбежно приводит к откликам на всех других уровнях и изменяет текущее состояние организма человека [3]. Реализация принципа целостности обязывает исследователей рассматривать различные аспекты индивидуальности во всем многообразии их взаимосвязей и взаимодействия

«Любому явлению психики присущи две неотрывные друг от друга характеристики, взаимно определяющие друг друга. Первая - это специфически психическое содержание, вторая - пространственно-временна́я организация» [2, с. 153]. Человек функционирует психически в реальном и индивидуальном пространстве и времени - пространственно-временно́м континууме. Индивидуальные пространство и время соответствуют пространственно-временной организации парной работы полушарий мозга. Участие полушарий мозга в реализации различных пространственно-временны́х отношений подтверждается клиническими данными. В исследованиях Брагиной Н.Н. и Доброхотовой Т.А. «гипотеза об асимметрии полушарий как о выражающей собой особую пространственно-временную организацию функций целого мозга основана на сравнительном анализе психопатологической симптоматики избирательного 
поражения мозга правшей и левшей. Нарушение симметрии функций пространственно противоположных полушарий мозга в этой гипотезе предполагается опосредованным временем. Функциональный вклад правого и левого полушарий в формирование психики человека предполагается различным потому, что полушария в их парной работе функционируют несходно во времени. Парная работа осуществляется в настоящем времени так, что правое полушарие опирается на прошлое, левое - на будущее время» [2, с.156]

Использование системного принципа в изучении феномена пространственно-временной организации мозга позволяет раскрывать новые ракурсы реализации взаимодействия мозг - психика.

Целью нашего исследования является актуализация принципа целостности (системного подхода) в отношении пространственно-временно́й организации мозга через изучение корреляций латеральных (пространственно асимметричных) признаков человека с его индивидуальными, временными, особенностями.

Гипотеза нашего исследования предполагает, что пространственно-временная организация мозга проявляет себя через определенные психофизиологические показатели, а системный подход к изучению этой организации мозга можно реализовать с использованием коэффициента корреляции.

\section{Материалы и методы исследования}

В обследовании приняли участие студенты Тихоокеанского государственного университета в возрасте 18-27 лет в количестве 159 человек. Исследование проводилось в утренние часы в состоянии физического и психического покоя. В качестве индивидуальных латеральных пространственных показателей были использованы элементы индивидуального профиля асимметрии. Профиль латеральной организации мозга, или индивидуальный профиль асимметрии (ИПА), рассматривается как фактор, обеспечивающий индивидуальную специфику двигательных функций. Индивидуальный профиль асимметрии по моторным и сенсорным показателям определяли с помощью тестов и опросника; оценивали в баллах, а затем высчитывали среднее значение уровня асимметрии в процентах.

По результатам тестирования выделяют следующие типы сенсорно-моторной асимметрии (ИПА): 1) тип 1: процент латеральности в баллах составляет от -100\% до -50\% - это сильный левосторонний профиль; 2) тип 2: от $-50 \%$ до -10 \% -частичный левосторонний профиль; 3) тип 3: от -10\% до +10\% - неопределенный, равносторонний профиль; 4) тип 4: от +10\% до +50 \% - частичный правосторонний профиль; 5) тип 5: от +50 \% до +100\% - сильный правосторонний профиль.

Для оценки временных показателей были выбраны: тест Ф. Халберга - определение «чувства времени» по индивидуальной минуте (ИМ), оценка скорости простой зрительно-моторной реакции с помощью компьютерного аппаратного комплекса «НС-ПсихоТест» (ПЗМР) и оценка суточных хронотипов по методике Хорна-Остберга.

\section{Результаты исследования и обсужление}

При оценке профилей латеральной организации в обследуемой студенческой группе были получены следующие результаты: 67 \% студентов были отнесены к 5 типу, с сильным правосторонним профилем по моторной и сенсорной асимметрии; 29 \% студентов были отнесены к 4 типу, с частичным правосторонним профилем; 3\% составили студенты с левосторонним профилем и $1 \%$ с неопределенным профилем [10].

Проведенные нами исследования по вычислению коэффициента корреляции профиля асимметрии с индивидуальной минутой, как показателя «чувства времени», продемонстрировали достоверные результаты:

$r=0,419$, что достоверно при $p \leq 0,01$ по двустороннему критерию [10]. Данные результаты показывают, что при увеличении доли правшества в индивидуальном профиле наблюдается тенденция к недоотмериванию эталонных отрезков времени (секунд) и увеличению значения «индивидуальной минуты» по нашей методике. И, наоборот, студенты с частичным левосторонним профилем асимметрии в большей степени проявляют тенденцию к «растягиванию» времени, их индивидуальное время течет более медленно, чем у большинства выраженных правосторонних по профилю студентов. Полученные результаты согласуются с исследованиями Тришина Е.С. и др. в отношении того, что «что люди с высокой адаптацией к нагрузкам (физическим, интеллектуальным, эмоциональным и др.) способны «растягивать» время (левши) или обладать эталонной ИМ (правши)» [8]

В нашем исследовании 77 \% студентов отмеривают минутный интервал замедленно, они растягивают время, поэтому метрическая минута у них субъективно укладывается в значения 38-54 секунды. Необходимо отметить, что умеренное растягивание, согласно данным исследователей, считается нормальным, значительное же замедление может быть проявлением доминирования тормозных процессов на фоне усталости, заболевания, неврастении, эмоционального ступора [4].

В работах В.А. Москвина подчеркиваются связи индивидуальных профилей латеральности с такими параметрами психологического времени как характер 
временны́х ориентаций, особенности восприятия и переживания времени. Отсчет длительности временных интервалов, в основе которого лежит сознательный счет с использованием определенного временно́го эталона, представляет собой специфический мозговой паттерн возбуждения и торможения, который в свою очередь определяется состоянием кортикального тонуса, уровнем активации мозговых структур, а также межполушарной мозговой асимметрией [5].

Одним из показателей временных, скоростных, процессов является время (скорость) простой зрительномоторной реакции. Общая скорость ПЗМР обусловлена анатомическими особенностями анализатора, свойствами нервных процессов, психофизиологическим состоянием организма и двигательно-координационным потенциалом обследуемого.

Оценка результатов ПЗМР производится на основе средних значений времени реакции и стандартного отклонения. Среднее значение времени реакции отражает среднюю скорость реакции и характеризует свойство подвижности.

Оценка общего результата скорости реакции по методике «Простая зрительно-моторная реакция» в группе студенческой молодежи показывает относительно высокие показатели функциональной подвижности тестируемых - среднее значение простой сенсо-моторной реакции составляет 270,7 мс, что свидетельствует о достаточно хороших психофизиологических ресурсах и, в целом, характеризует функциональное состояние исследуемых студентов, как находящееся в пределах психофизиологической нормы [11; 12].

Вычисление коэффициента корреляции индивидуального профиля асимметрии с быстротой реакции выявило его достоверную значимость при $r=0,517$ [11]. Полученные результаты подтверждают данные исследований Е.Б. Сологуб, согласно которым левши по сравнению с праворукими имеют более короткое латентное время двигательной реакции на свет, обеспечивающее успешность простых и быстрых действий, но меньшую скорость переработки сложной информации [7].

Е.Д. Хомская также свидетельствует о том, что праволатеральные индивиды от природы являются двигательно более активными и обнаруживают более высокую способность к произвольному ускорению такой активности [9].
Изучение распределения суточных биоритмов среди студентов по методике Хорна-Остберга показало, что в исследуемой студенческой группе преобладающим является «дневной тип», или «голубь», что составляет 54 \% от общего количества респондируемых студентов. На втором месте по рейтингу суточных биоритмов находятся представители «вечернего типа», «сова», - 33 \% обследуемых и, меньше всего среди студентов ТОГУ людей «утреннего» типа, или «жаворонков» - 13 \% [13]. Сопоставление взаимосвязи количественных значений суточного хронотипа и индивидуальной минуты с использованием коэффициента корреляции с дальнейшей проверкой на достоверный уровень значимости показало, что $r=0,596$ при $p<0,05$ [10; 13]. Таким образом, подтверждается предположение о том, что именно люди вечернего типа субъективно растягивают время, таким образом их внутреннее время течет медленнее, чем объективное метрическое. Следовательно, у представителей «вечернего» типа могут возникать проблемы во временно́й ориентации, что часто проявляется в неправильной оценке своих временных действий и возможности нередких опозданий.

Оценка корреляционных отношений показала наличие достоверных корреляций в обследуемой группе студентов между суточным хронотипом и индивидуальным профилем асимметрии - $r=0,312$, при $p<0,05$. Корреляция показывает, что для студентов «утреннего» типа в большей степени характерно наличие правостороннего профиля асимметрии.

\section{Зак^ючение}

В нашем исследовании показано, что реализация системного подхода в изучении пространственновременны́х отношений в деятельности мозга может быть частично осуществлена использованием статистического метода оценки корреляционных взаимосвязей. Такой подход позволяет в определенной степени обнаружить известные взаимоотношения, но для понимания и раскрытия этих взаимодействий необходимы другие методы инструментального исследования, которые на современном этапе развития науки пока не разработаны или не применимы для человека. Тем не менее, определение отношений между компонентами пространственновременно́й организации мозга как свойства этой системы позволяет оценивать другие характеристики этой сложной многомерной структуры, такие как результативность, функциональность, адаптивность, устойчивость, способность к саморегуляции и развитию. 
2. Брагина, Н.Н. Функциональные асимметрии человека [Текст] / Н.Н Брагина, Т.А. Доброхотова. - М.: Медицина, 1988. - 468 с.

3. Мерлин, В.С. Психология индивидуальности: Избранные психологические труды / В.С. Мерлин; Под ред. Е.А. Климова. - М.: Изд-во Московского психолого-социального института; Воронеж: Изд-во НПО «МОДЭК», 2005. - 544 с.

4. Моисеева, Н.И. Время в нас и время вне нас. / Н.И. Моисеева - Л.: Лениздат, 1991. - 156 с.

5. Москвин, В.А. Нейропсихологические аспекты исследования временной перцепции у здоровых лиц / В.А. Москвин, В.В. Попович // I Международная конференция памяти А.Р. Лурия. Сб. докладов под ред. Е.Д. Хомской, Т.В. Ахутиной. - М.: Изд-во РПО, 1998. - С. 160-166.

6. Психология человека от рождения до смерти / под ред. А.А. Реана. - СПб.: ПРАЙМ- ЕВРОЗНАК, 2002. - 656 с.

7. Сологуб, Е.Б. Корковая регуляция движений человека. - М.: Медицина, 1981. -184 с.

8. Тришин, Е.С. Хронотопобиологические свойства спортсменов индивидуальных ситуационных видов спорта с учетом латерализации полушарий / Е.С. Тришин, Е.М. Бердическая, Е.М. Тришин, А.С. Голубева // Физическое воспитание и спортивная тренировка. - №2. -2020. -С. 114-121.

9. Хомская, Е.Д. Нейропсихология индивидуальных различий: Учеб. пособие / Е.Д. Хомская, И.В. Ефимова, Е.В. Будыка, Е.В. Ениколопова. - М.: Рос. Пед. Агентство, 1997. - 281 с.

10. Ядрищенская, Т.В. Индивидуальный профиль асимметрии и некоторые психофизиологические показатели студентов ДВГГУ / Т.В. Ядрищенская // Научные чтения «Биология. Экология. Образование /под ред. В.Т. Тагировой, А.Ф. Дулина. - Хабаровск: Изд-Во, ДВГГУ - 2009. - С.80-85.

11. Ядрищенская, Т.В. Психофизиологические показатели и успеваемость студентов ДВГГУ / Т.В. Ядрищенская, Е.Г. Жулий // Научные чтения «Биология. Экология. Химия. Образование»: сб. научных трудов по итогам работы 58 научной конференции преподавателей ДВГГУ / под ред. В.Т. Тагировой, А.Ф. Дулина. - Хабаровск: Изд-во ДВГГУ, 2013. - С. 127-134.

12. Ядрищенская, Т.В. Психофизиологические показатели в аспекте адаптации студентов к учебной деятельности в вузе / Т.В. Ядрищенская // Наука и образование на российском Дальнем Востоке: современное образование и перспективы развития. - Т2. - Тихоокеанский государственный университет, Хабаровск, 2016. - С. $380-385$.

13. Ядрищенская Т.В. Циркадианные биоритмы студентов и их значение в учебной деятельности / Т.В. Ядрищенская // Материалы международной научнометодической конференции «Проблемы высшего образования» Хабаровск, 6-8 апреля 2016 г. - Том ІІ. - ФГБОУ ВО Тихоокеанский государственный университет, Хабаровск г, 2016. - С.176 - 178.

с Я дрищенская Татьяна Васильевна (tagir.on-line@mail.ru).

Журнал «Современная наука: актуальные проблемы теории и практики»

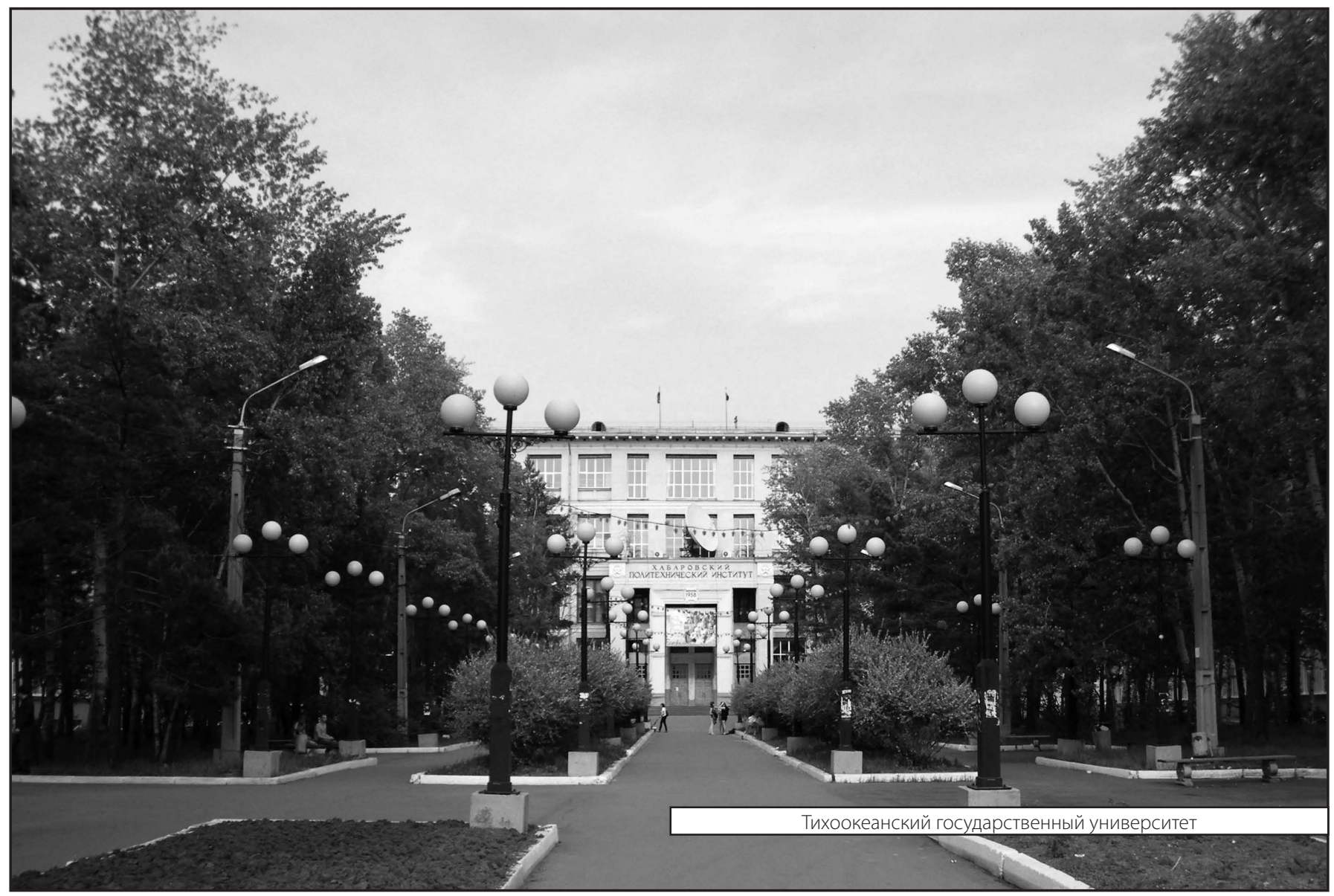

